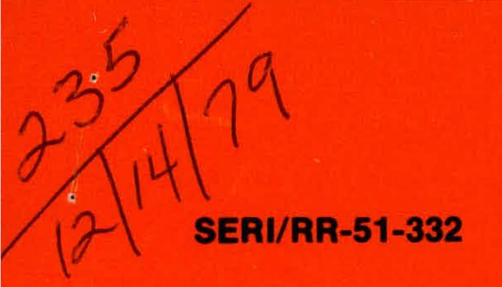

October 1979

\title{
A Proposition on Energy Analysis and Economic Efficiency
}
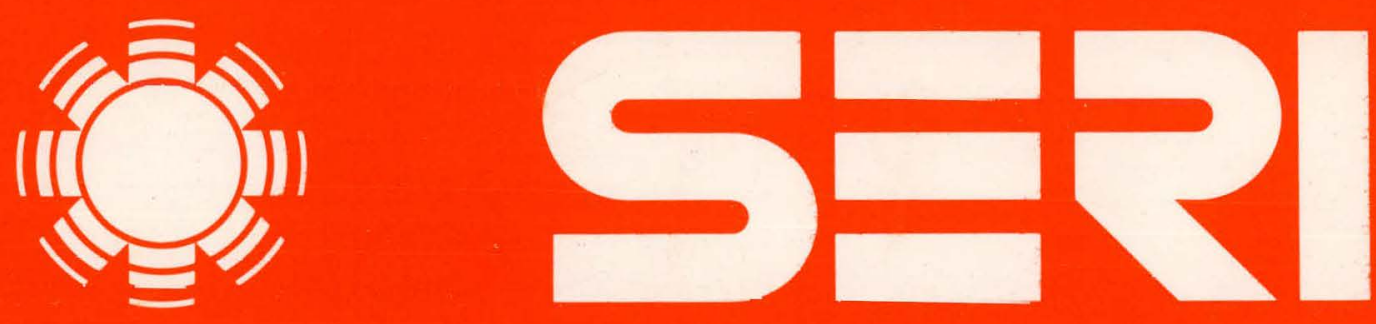

Solar Energy Research Institute A Division of Midwest Research Institute

1536 Cole Boulevard

Golden, Colorado 80401

Operated for the

U.S. Department of Energy under Contract No. EG-77-C-01-4042

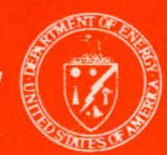




\section{DISCLAIMER}

This report was prepared as an account of work sponsored by an agency of the United States Government. Neither the United States Government nor any agency Thereof, nor any of their employees, makes any warranty, express or implied, or assumes any legal liability or responsibility for the accuracy, completeness, or usefulness of any information, apparatus, product, or process disclosed, or represents that its use would not infringe privately owned rights. Reference herein to any specific commercial product, process, or service by trade name, trademark, manufacturer, or otherwise does not necessarily constitute or imply its endorsement, recommendation, or favoring by the United States Government or any agency thereof. The views and opinions of authors expressed herein do not necessarily state or reflect those of the United States Government or any agency thereof. 


\section{DISCLAIMER}

Portions of this document may be illegible in electronic image products. Images are produced from the best available original document. 
Printed in the Uniter States of America Available from:

Natinnal Technical Information Scrvice

U.3. Depurtinent of Commerce

5285 Port Royal Roud

Springfield, VA 22161

Price:

Microfiche $\$ 3.00$

Printed Copy $\$ 4.00$

\begin{abstract}
NOTICE
This report was prepared as an account of work sponsored by the United States Government. Neither the United States nor the United States Department of Energy, nor any of their employees, nor any of their contractors, subcontractors, or their employees, makes any warranty, express or implied, or assumes any legal liability or responsibility for the accuracy, completeness or usefulness of any information, apparatus, product or process disclosed, or represents that its use would not infringe privately owned rights.
\end{abstract}


SERI /RR-51-332

UC CATEGORY: UC-63A

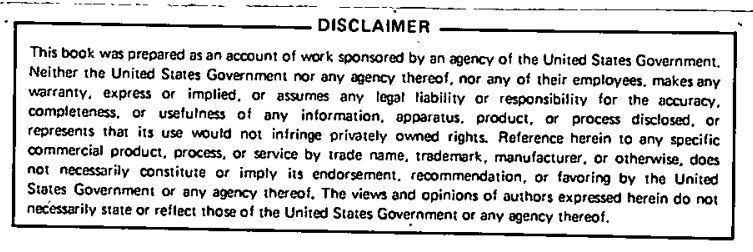

A PROPOSITION ON ENERGY ANALYSIS AND ECONOMIC EFFICIENCY

DONALD I, HERTZMARK

OCTOBER 1979

PREPARED UNDER TASK NO. 5121

\section{Solar Energy Research Institute}

1536 Cole Boulevard

Golden. Colorado 80401

A Division of Midwest Research Institute

Prepared for the

U.S. Department of Energy

Contract No. EG $\cdot 77 \cdot C \cdot 01 \cdot 4042$ 
THIS PAGE

\section{WAS INTENTIONALLY LEFT BLANK}


This report was prepared as a part of the Cost Reduction Strategies Task that is concerned with, among other things, end-use matching for energy technologies. The report describes the interaction of some economic and physical measures of efficlency in determining the prices of energy commodities and the desirability of using scalar measures of cost or efficlency in the evaluation of alternative technologies.

This work is funded by the Division of Energy Technology of the U.S. Department of Energy. The leader of this task is James Doane of SERI's Policy Ana 1ysis Branch. The author is a staff economist in that branch.

The author wishes to acknowledge the helpful comments of James Doane, Bert Mason, and Dave Kearney of SERI. John Steinhart of the University of Wisconsin also has provided invaluable help and inspiration throughout the gestation of this paper and other papers on similar subjects.

Approved for:

SOLAR ENERGY RHSEARCH INSTITUTE 
THIS PAGE

WAS INTENTIONALLY

LEFT BLANK 


\section{SUMMARY}

This report gives some analytical results of an attempt to simultaneously optimize economic and thermodynamic efficiency. The attempt to impose complete mathematical rationality and consistency on the pricing of energy commodities fails since it is not possible to consistently weigh purely physical efficiency measures, much less social factors. This means that energy or entropy theories of value must suffer the fate of other single-factor theories, such as the labor theory of value. Such a single factor theory cannot adequately handle such questions as fixed capital, subjective utility, and contradictory constraints on economic choice.

Nevertheless, the use of both materlal balance and entropy analysis is valuable for evaluating nonmarket decisions, as well as identifying opportunities for process improvements. That is, economic and thermodynamic analyses are complementary in that they ask different types of questions and express the answers in noncomparable dimensions. Th1s complementarity is a type that avers that each mode of analysis asks different questions from different perspectives. 


\section{THIS PAGE}

\section{WAS INTENTIONALLY LEFT BLANK}




\section{TABLE OF CONTENTS}

Page

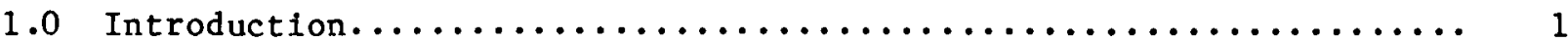

1.1 First Law (Conservation) Efficiency.................. 1

1.2 Second Law (Thermodynamic) Efficiency................... 2

2.0 A Model for Thermodynamic Matching.................... 4

3.0 Process Optimization and Economic Efficiency.............. 7

4.0 Energy Analysis and Economics: The Need for Complementarity...... 10

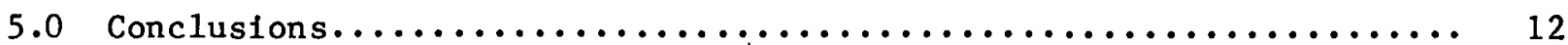

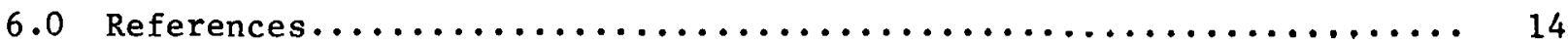

\section{LIST OF FIGURES}

3-1 First Law Efficiencies (e) as a Function of Second Law

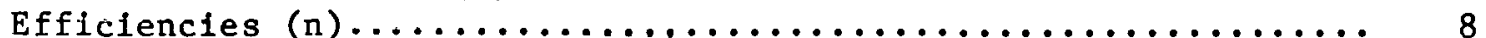




\section{SECTION 1.0}

\section{INTRODUĆTIOA}

In a recent paper on the relationship between economic and thermodynamic optima, Berry, Salamon, and Heal gave some conditions under which a competitive firm would be thermodynamically and economically efficient (1978, pp. 125137). Among other things, their proposition depended upon letting the highest thermodynamic use set the opportunity cost of avallable work. Later in the paper, the authors considered thermodynamic effictency in the context of conservation of mass (pp. 135-136). As their argument showed, simultaneous achievement of mass efficiency and energy efficiency is unlikely.*

In this paper, that proposition is formalized to show that first law (conservation) and second law (thermodynamic) efficlencies are in fact linearly independent so that achievement of an optimum with respect to one measure will not mean anything in particular with respect to the other measure. Achievement of a high second law efficiency of ten will require polictes that actually reduce first law efficiency. In addition, the suggestion made by Berry, Salamon, and Heal that available work be allocated on the basis of cascading from one use to the next is elaborated on here (1978, p. 132).

\subsection{FIRST LAH (CONSERVATION). EFPICIENCY}

The first law efficlency relates outputs to inputs according to the general formula :

$$
\eta=\frac{\text { Useful energy outputs }}{\text { Total energy inputs }}=\frac{\Phi}{\beta_{\alpha}} \text {. }
$$

As explored more fully in Gilliland (1978) and Thomas (1977), among other sources, the first law efficiency measure can be used to analyze the feasibility of alternative projects from an energy perspective. In the form given by $\mathrm{Eq}$. 1, the units are humugeneouo joules or calories, and the efficiency is simply a question of calculating (often quite tedious) the joules available al the final step relative to those inputs through all stages of the process.

That is, from Eq. 1 we can determine whether a proposed energy project will return the total "investment" of energy in that project. For example, if the first law efficiency of residential water heating by gas produced from coal has a particular value, then we have accounted for the total input of energy. If the first law efficiency of coal gasification is 0.35 (i.e., 0.35 of the Btu put into the process--the coal. and external energy inputs--are retained in the gaseous form) and if this gas is piped with an efficiency of 0.9

*The first law states that energy can be neither created not destroyed but only transformed. The second law states that the entropy (unavailable energy) of the unfverse or of any closed system moves continuously and irreversibly toward a maximum. The third law of thermodynamics states that absolute entropy is never achieved (Pauli 1973, pp. 6,7). 
and burned in the house at $\eta=0.5$, then one obtains the overall value of $\eta=0.35 \times 0.9 \times 0.5=0.158$. Thus, only $16 \%$ of the original fuel value of the coal is delivered usefully to the hot water tank.

To look at an alternative, suppose that you wish to heat water with electricity derived from coal. Suppose that the electricity is generated at $\eta=0.45$ and that transmission losses are about 0.25. Assume further that the electricity transmitted to the water heater is entirely transformed to heat. For this process, $n=0.45 \times 0.75 \times 1=0.34$, which is considerably better than the result from gasification of coal.

\subsection{SECOND LAH (THERHODYNAMTC) ETTICIENCY}

$\Lambda$ different story ig told by the second law efficienoy measuit which relates $B_{u}$ (total eneigy inputs) to the minimum input of available work required to perform the task; i.e.,

$$
e=\frac{\beta_{\text {min }}}{\beta_{\alpha}}<1 \text {. }
$$

Unfortunately, available work (unlike the fictional homogeneous joule) is not easily described by a quantitative measure. In entropy analysis, we look at the irreversible decrease in the capacity of a system to perform work as the indicator of the increase in entropy (unavailable energy, or disorder). For the example given above, we cunsider the available work of the hot water, $\dot{B}_{\text {min }}$, relative to the available work of the fuel, $\beta_{\alpha}$. Thus, the hot water still contains available work although it is at a lower temperature than is possible, given the work potential of the coal.* To measure the available work that remains in the hot water, we take the ambicnt temperature, $\mathrm{T}_{0}$, the combustion lemperature, $T_{1}$, and the hot water temperature, $T_{2}$, to get

$$
e=\frac{1 \cdots \mathrm{T}_{0} / \mathrm{T}_{2}}{1-\mathrm{T}_{0} / \mathrm{T}_{1}}
$$

If electriclicy were provided to a household at $\eta=1$, the second law efficipncy of using this electricity to heat water wuld be $e=0.126$. With $\eta=0.34$, The overall thermodynamic efficiency is $e=0.34 \times 0.126=0.043$ which means that 0.957 of the mass of the fuel has been irreversibly degraded without performing any useful work. This indicates that encrgy for a task, such as heating watur, is not reeded in such an intense form.

*In thermodynamic analysis, one must refer back to primary energy sources; that is, electricity and SNG are not considered the primary energy sources. 
It is from the above type of analysis that the concept of end-use matching has gained currency. That is, when judging the suitability of given technologies for the performance of a given task, the second law efficiency indicates the degree of matching between the quality of energy provided and the quality of energy required for the task. However, since improved source-use matching requires increased time beyond a certain point, there is a clear trade-off to be made between time and improved thermodynamic performance.* What second law analysis adds to one's understanding of alternative energy proposals is the notion of trade-offs among time, efficiency of energy resource use, and efficiency of capital equipment use. Notice that all three of these factors are problematic areas for standard economic theory.

*That is, the $\beta_{\text {min }}$ is calculated according to infinitely slow, reversible processes. In a real-time process, the $\beta_{\min }$ figure would be higher since the speed-up would require additional energy use. Thus, second law efficiencies of 1 are not achievable since they would require infinite time (see APS 1975, pp. 35-41, for a more complete explanation of this). Source-use matching generally refers to the temperature matching of a process. That is, if a process rcquires lnw temperatures and the source provides high temperatures, then there is a poor thermodynamic match between source and usc, and e is correspondingly low as in the alternative presented in section 1.1. Since time itself is a vanishing resource, the trade-off between thermodynamic efficiency and time has provoked both analytical interest (IFIAS report 1978, p. 184) and philosophical speculation (Spreng 1978). The idea of putting time explicit1y into the production function was first raised by Georgescu-Roegen in relation to the differences between factory and agricultural production functions (1971, p. 241). 


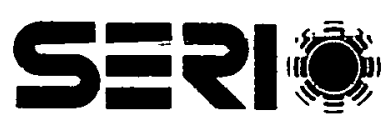




\section{SECTION 2.0}

\section{A MODEL FOR THERMODYNAMIC MATCHING}

For an economically efficient allocation of resources, we desire to know the opportunity cost of available work with respect to other resources. Since this cannot be done directly through the market for "enthalps" (such a market does not exist), it must be approached indirectly via "shadow" or imputed prices.*

A specification of a given energy source would start from a particular quality of energy and then specify the quantity in joules as well as the other relevant characteristics of the resource. Several problems appear at this point, and it is worth exploring them in some detail. At first glance, it would appear that all of the energy sources will have prices that use the corresponding measures of available work as a reference point. The problem that appears when using the standard apparatus of static production theory is the need to handle joint products, because many of the virgin energy sources are capable of having more than one output over the course from their highest thermodynamic state to the ambient state. As waste heat from a high quality use forms the input of the next sequenced use, it is necessary to determine jointly the availability of the different levels of energy in order to optimize a given system. This is a problem for which modern control theory has been developed and appears to be eminently suitable. T1me does not enter except as it has the attributes of a spatial coordinate. A model of the type to be given below is proper for the design of a factory or housing complex, but it is not correct for overall policy regarding the allocation of available work.** As an example of such analysis, consider the following model.

Define:

$\mathbf{x}=\mathbf{a}$ vector of state variables denominated in descending order of energy quality;

*For example, see Intriligator (1971, pp. 60-62).

**This refers to the distinctions between historical time and "dynamic" time that are discussed by Ccorgescu-Rnegen (1971, pp. 134-140), Robinson (1962, pp. 23-29), and Hicks (1976). That is, in historical time one does lut asgume perfect loresight or surprise-free outcomes. Intertemporal optimization is impossible since the terminal conditions are unknown. In dyramic time, the future is determined simultaneously. One period is just like another in time since there are no surprises. Analytically, there would be no difficulty in making time run backwards. For decisions in which irreversibility is an important attribute, such simultaneous maximization destroys the very aspect of time that irreversibility conveys. There have been some attempts to include irreversibility in exhaustible resource models (Arrow and Fisher 1974), but one has yet to see such models perform empirically. 
$a=a$ target level of performance for each of the $x_{i}$ variables as determined by the technical conditions of production (the technical frontier again);

$u=a$ vector of control variable which determines the subsequent $x_{i}$;

$W=a$ weighting or cost matrix giving the cost of the derivations of the $x_{i}$ variables from their target levels, $a_{i}$;

$\mathrm{U}=\mathrm{a}$ welghting matrix giving the costs of the control function;

$\gamma=$ the adjoint variable whose values comprise the vector of shadow prices for various grades of available work;

$A=$ the coefficient matrix of the state equation giving the time path of $x$ as a function of its previous values and those of the control variable, $u$; and

$B=$ the vootor tlial gives the effect of the values of $u$ on the subsequent values of $x$ in the state equation.

The problem is one.. of minimizing the cost of choosing the technologies that will utilize the available work, $x$, at its various quality levels. That is,

$$
\begin{aligned}
&\left.\min J\left(x_{0}, u, t_{0}, t_{1}\right)=\frac{1}{2} \int_{t_{0}}^{t} 1(x(t)-a(t))^{\prime} w(x(t)-a(t))+u(t)^{\prime} U u(t)\right] d t \\
& s \cdot t \cdot x\left(t_{0}\right)=x_{0} \\
& x\left(t_{1}\right)=x_{1} \\
& \dot{x}=A(t) x+B(t) u
\end{aligned}
$$

Utilizing the maximum principle of optimal control theory (Intriligator 1971, pp. 344-369) and making the simplifying assumption that $A$ and $B$ do not vary with time, we may define the Hamiltonian function as

$$
H=\frac{1}{2}\left[(x(t)-a(t))^{\prime} W(x(t)-a(t))+u(t)^{\prime} U_{1}(t)+Y(A x+B u)\right] \text {. }
$$

By the maximum principle, the conditions for a minimum uf $H$ that will give a minimum of Eq. 3 are:

$$
\frac{\partial H}{\partial u}=u^{\prime} U+\gamma B=0, \quad-\frac{\partial H}{\partial x}=-(x(t)-a(t))^{\prime} W-\gamma A=0=\frac{d \gamma}{d t} .
$$

Equation 5 can be solved to give the optimal control $u^{*}=-U^{-1} B^{\prime} \gamma$, which is then. Inserted 1nto the state equation to obtain a numerical solution (this is usually done. by discrettzing the model and using difference equations). $\gamma$, the adjoint varfable, gives the shadow price of available work at each state of thermodynamic quality. other constraints would need to be added to this model to achieve greater realism. The number of potential shadow prices becomes quite large in this event. As the number of special factors increases, we would expect the imputed values of the different energy products to become 
increasingly tied to a specific design situation. Without consideration of other factors, this situation specifically obviates many of the general conclusions about energy prices to be gained from second law analysis.*

We should stress that this model is not an economic optimum since it was constrained to be in the neighborhood of a particular second law target.** In a similar though simpler way, the maximization of net energy output can be modeled to yield shadow prices of the various energy inputs using conventional static mathematical programming techniques.

For example, to maximize the net energy output $n^{\prime} x$ subject to resource constraints $b^{\prime} x \leqslant B$, we obtain the problem,

$$
L=n^{\prime} x+\lambda\left(B-b^{\prime} x\right),
$$

with Kuhn-Tucker conditions,

$$
\begin{aligned}
& \frac{\partial L}{\partial x}=n^{\prime}-\lambda b^{\prime}<0, x \frac{\partial L}{\partial x}=0, \text { and } \\
& \frac{\partial L}{\partial \lambda}=B-b^{\prime} x \geqslant 0, \quad \lambda \frac{\partial L}{\partial x}=0 .
\end{aligned}
$$

Assuming that the resource is entirely used up $(\lambda>0)$, then $\lambda$ gives the imputed or shadow price of the resource, $x$. In this way, one could determine whether a given set of processes is both thermodynamically and economically efficient. If we remove the target level of thermodynamic efficiency and put in a quantity (of output) constraint, then an excess of costs in the case given above versus the latter implies that the target level of thermodynamic efficiency carries economic penalties with it. Such results could be expected to vary according to whether energy and capital are primarily substitutes or complements in a particular process. The impact figures would not necessarily jibe with those of the optimal control model since the model of Eq. 6 and Eq. 7 achieves efficiency with respect to the inputs of energy, whereas the optimal control model achieves efficiency with respect to end uses of energy. This difference forms the crux of the proposition presented below.

*This does not mean that the concept is useless. Rather, since all of the shadow prices are jointly determined, each design situation will call for a different number of energy products. It is to clarify this shadow price determination and the capital-energy trade-offs that need to be made in each situation that the hybrid economic-thermodynamic model has its greatest use.

**This allows, among other things, a determination of the costs of achieving various levels of energy conservation since the target level, a, can be varied easily. 


\section{SEPI용}




\section{SECTION 3.0}

\section{PROCESS OPTIMIZATION AND ECONOMIC EFFICIENCY}

Given an objective of optimizing the physical performance of a process or system, we seek a means of obtaining a weighting or "price" of joules in terms of available work (or of available work in terms of joules) that will allow us to accomplish this goal. Unless we can establish the proper trade-off between these two measures, we cannot establish a physical measure of performance that is consistent with respect to both first and second law principles.

We now show that, in the general case, this is not possible; 1.e., there does not exist a "price" of avallable work in terms of joules (or vice versa) that is consistent. The first step is to show that $n$ and $e$ are linearly independent.

Assume the contrary; $1 . e .$, assume

$$
\frac{\beta_{\min }}{\beta_{\alpha}}=\alpha \frac{\phi}{\beta_{\alpha}}+b .
$$

This is equivalent to

$$
\beta_{\min }=\alpha \phi+b \beta_{\alpha} .
$$

Differentiating this expression with respect to $\phi$ gives

$$
\frac{\mathrm{d} B_{\min }}{\mathrm{d} \phi}=\alpha
$$

An increase in useful energy output causes the minimum available work necessary to run the process to change by some constant. This cannot occur since $B_{\min }$ is calculated without reference to any actual process (APS 1975, pp. 24-35). Thus, $\eta$ and e are linearly independent.

The second step is to show that complementary information is obtained from net energy analysis and from entropy analysis. That is, it cannot be weighted optimally in a scalar-valued function. If the first and second law efficiencies are linearly independent, then the vectors of these efficiencies with respect to given energy processes also will be linearly independent. The conditions for attaining an extreme value with such a vector-valued function are given by Athans and Geering (1973). For our interest, the requirement is that $n=e$. That is, the task must be mechanical work with the necessary conditions being met for no uther sourcc-uee combinations.*

As proof of this, let $z$ be a vector-valued function of the two quadratic criterion functions, $\chi^{\prime} e x$ and $\chi^{\prime} n \chi$, where $\chi$ is energy use in joules (ur capital expenditures on energy use, etc.). We propose to infimize $Z$ without constraint;

*This condition will be met by electricity generatiun and fow other real processes. Figure 3-1 displays the lack of any l1near dependence of $n$ and $e$. 
i.e.,

$$
\inf _{x} z=\frac{x^{\prime} e x}{x^{\prime} n x}
$$

The necessary conditions are

$$
\frac{\partial z}{\partial x}=\frac{2 x^{\prime} e}{2 x^{\prime} \eta}=0
$$

i.e., $2 x^{\prime} e=2 x^{\prime} n$, or $e=n$, which is only true in general for tasks in which the ouput is meshanical work (see Flg. 3-1).

The reason for seeking a means of welghting first law and second law considerations in a consistent manner is that such techniques are at the heart of economic planning via shadow prices. And when we consiller the other qualilative and quantitative characteristics of energy resources (portability, storability, cleanliness, convenience, etc.), we see that an economicaliy efficient a1incation of resources will attain some sort of trade-off among these factors. If the weighting cannot be consistent, then allocation via shadow prices will not be optimal relative to the "irrational" processes of real markets.* However, the inconsistency property means that there is no unique way in which available work is counted in arriving at market prices. Another way of looking at the linear independence property is to note that Eqs. 3, 4, and 5 give an optimum allocation of available work relative to a task, a, while Eqs. 6 and 7 give an optimum relative to a commodity, $x$. The distinction between task optima and commodity optima is crucial since economic theory has focused more strongly on the latter than on the former. It is, thus, possible to have an efficient allocation of commodities which is quite inefficient in ite task perfürmance.

*We may interpret this to say that an energy or entropy theory of value is an analytical impossibility. On the other hand, the propositiun shows that each system of relative energy prices that comes out of a particular income distribution and consumption set in real markets will have components that cannot be analytically duplicated. This means that the distance of an aggregate market energy price from its shadow price has no normative implications. Only at the project level may we make inferences about market vs. shadow prices. 


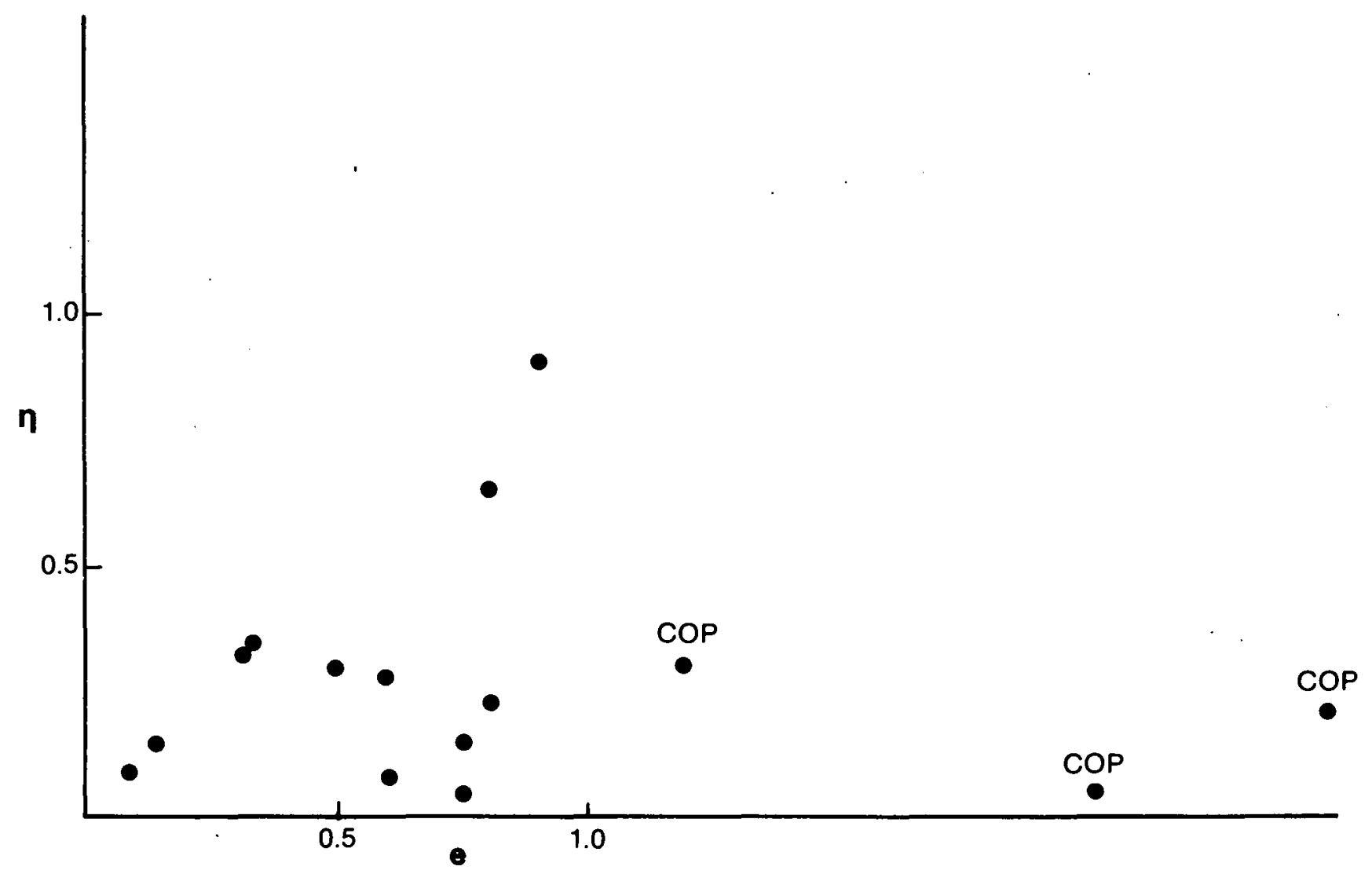

Source: Data from Ayres (1978) and Ross and Williams (1977)

COP Coefficient of Performance for First Law Efficiencies 1.0

Figure 3-1. First Law Efficiencies ( $\eta$ ) as a Function of Second Law Efficiencies (e) 
SERI 


\section{SECTION 4.0}

\section{ENERGY ANALYSIS AND ECONOMICS : THE NEED FOR COMPLEMENTARITY}

We may distinguish among three forms of interaction of energy analysis with economic analysis. The first, energy content pricing, has been attacked by numerous authors* and need not be discussed extensively here. As with other single-factor theories of value, it cannot explain intertemporal allocation and it is inconsistent with the notion of subjective utility. Net energy analysis, like cost-benefit analysis, is a method of accounting that is an aid (and no more!) in the ranking of alternative projects. The analyst must choose an accounting stance (draw the boundaries of the system) and then proceed. The results, expressed in ratio form, do not indicate anything other than whether a project is feasible with respect to that measure. The social worth of the project cannot be determined from a ratio; if the measure is incomplete, then the analysis is also.

However, net energy analysis has some distinctly useful features that complement other schemes of analysis, especially microeconomic analysis. We can show that a pricing scheme which is set up to allocate joules will achieve a maximal net energy ratio, subject to constraint.** of course, energy markets are highly imperfect, and persistent inflatton leads to distortions in capital allocations due to uncertainty with respect to relative rates of inflation of various commodity groups. Net energy analysis, therefore, provides a check on market operation that helps to identify impacts that may be obscured through market imperfections or myopic expectations. In addition, net energy or material balance analysis forces the analyst to account for the energy-material

*For example, Huettner (1976); Berry, Salamon, and Heal (1978).

**This is explored in detail by Hertzmark (1978). Intuitively, the argiment is that a competitive economic system which allocates homogeneous joules in markets will do so at least cost and will only choose a lower efficiency process (first law) if the associated costs (capital, etc.) make up the differential in energy costs. Thus, conservation, in a first law sense, is its own reward. Once qualitative attributes of energy (e.g., available work) are introduced, this neat consistency of allocation falters.

An intertemporal optimization model that uses continuous production functions is 111-equipped to change from a situation of roughly onstart returns to one of sharply diminishing returns and then to constant returns again as a new production process is established. That 1s, we can expect a shift in the production function that will be dependent upon what prices rule at the time for fnputs and outputs. Unlike the example given in Berry, Salamon, and Heal (1978, p. 136), the old production function is not available since the one quality upon which 1 t was predicated did not exist at that time. 
flows of a system and may help in the identification of potential adverse impacts on the environment or economy.*

In reality, net energy analysis cannot elfminate economic or social analysis since the true output of an economic system is the enjoyment of $11 \mathrm{fe}$ through the performance of tasks. The proper physical efficiency measure for task performance is a qualitative one, such as the second law efficlency. An ecnnomic system that operates on second law principles will often suboptimize many first law efficiencies (e.g., in electric power generation) as a means of optimizing task performance.

For example, consider a fluidized bed combustion unit that can generate eler:tricity alone at $e=\eta=0.45$. If this electricity is being used for low-temperature heat, then a task effiriency io obtained of roughly the same value that was given on page $2(.0 / 3)$. Consider a cogeneration scheme for which a smal1 portion of the avallable work is used to heat water $\left(80^{\circ} \mathrm{C}\right)$ for distribution to houses. The first law efficiency of electrical generation drops to $n=$ 0.27 , while the overall second law efficiency drops to $e=0.36$. However, consider the use of this hot water for household use. With $n=0.43$ for hot water generation and a distribution loss of 0.10 , we obtain $e=0.43 \times 0.90 \times$ $0.77=0.297$, the 0.77 being the pure second law efficiency of using $80^{\circ} \mathrm{C}$ water to provide household water heat. This indicates an increased efficiency in the use of fuel in spite of a slight drop in the overall first law efficiency to $0.32 . * *$

Unfortunately, the noncardinality of enthalpy prevents its being assigned $a$. consistent price that is independent of the source of the available work, as well as its other characteristics. That is, there exists no entropometer that is capable of measuring the change in state of a macrosystem (Ceorgescu-Roegen 1971 , p. 101). Thus, energy pricing is often partially thrown back to first law principles which, though inaccurate, are at least comprehensible and relatively simple in terus of dimensionality. This returns us to the original problem. Prices are based on a weighting of first and second law considerations, though not consistently, since this is definitionally impossible according to our proof.

*A11 calculations are from Hertzmark (1978, Tables 6.3 and 6.4 ).

**An economic analysis, even when properly performed, cannot be expected to predict ouch phenumena as the adverse impacts of the uses of, say, synthetic organic chemicals. Future markets for natural environments are scarcely efficient if they exist. Similarly, economic models cannot accurately determine the impacts of changing from, for example, sulfide to silicate bonds in metals processing since such a change involves both discontinuities in the production function and nonlinearities in costs. 


\section{SECTION 5.0}

\section{CONCLUSIONS}

The implications of this exercise are several-fold. First, physical efficiency measures can complement economic efficiency measures since the economic measure must, of necessity, be an inconsistent compromise between the first and second law measures independently of market imperfections.

Second, since peoples' utility functions regarding the future are often far more complex than can be represented with a simple geometric discount factor,* then geometrically discounted present values are not always an accurate guide to making decisions; e.g., the identification of adverse environmental impacts or the achievement of a safe minimum standard of conservation of flow resources (Cirlacy-Wantrup 1968, pp. 251-268). As mentioned previously, material balance analysis provides useful information on a wide variety of environmental issues about which there is little or no economic data; e.g., atmospheric carbon dioxide, DDT, and other chemical pollutants. Presumably, the use of this accounting system should help us to keep track of cumulative environmental burdens and to estimate the inflection points of damage functions.

Third, the large number of unpriced intermediate goods within many modern industrial enterprises makes the maintenance of energy, as well as financial accounts, one means of monitoring the relative efficiencles of alternative operations.**

Fourth, for analytical purposes, the linear independence of e and $n$ would allow their use as constraints in optimization models with objective functionals denominated in money units. Such an approach is implicltly employed in environmental standards, and the argument on the grounds of energy-materials conservation is at least as strong, given the political and social constraints that also affect energy policy.. None of these modes of analysis forms a complete view of soctal decision making, though each has a role. It is important to keep in mind that markets do not exist for all energy commodities, particularly for varlous grades of "waste heat." An optimization model, such as Eqs. 3, 4, and 5, can help to determine proper prices for these resources on a very

* Page (1977) shows that intertemporal consistency is equivalent to obeying the optimality principle of dynamic programming. As long as one is consistent, the optimal path will remain the same from any starting point with the given time period. Introducing a nongeometric discount factor makes the starting poili crucial since a unique path will be determined for each point along the time line. If decisions are made according to such criteria (and it is reasonable to belleve that many conservation decisions fall into this category), then the social optimization will change our time in a seemingly inconsistent manner.

**Dow Chemical Company has kept energy and financlal accounts on its operations for a number of years (IFIAS 1978). 
disaggregated level since, clearly, we cannot have future markets in low-temperature heat. Policy recommendations that flow from this analysis include taxes on excessive waste heat loss (possibly accounted for with higher energy prices in general) and the use of entropy analysis to identify opportunities for process improvement and more efficient intra-firm analysis.

As a final point, it has been shown that the suggestion of Berry, Salamon, and Heal concerning simultaneous achievement of mass and energy efficiency is not only unlikely, but it is generally impossible (1978). The movement toward poorer grades of mineral deposits than are presently mined will provide data for empirical tests of this proposition. 


\section{SECTION 6.0}

\section{REFERENCES}

American Physical Society (APS). 1975. The Efficient Use of Energy: A Physics Perspective. Washington, D.C.: U.S. Government Printing Office.

Arrow, Kenneth J.; Fisher, Anthony C. 1974. "Environmental Preservation, Uncertainty, and Irreversibility." Quarterly Journal of Economics. Vol 88: May; pp. 312-319.

Athans, M.; Geering, H. P. 1973. "Necessary and Sufficient Conditions for Differentiable Nonscalar-Valued Functions to Attain Extrema." IEEE Trans. Control. Vo1. 18 (no. 2).

Berry, R. S.; Salamon, P.; Hea 1, G. 1978. "On a Relation between Ëconomic and Thermodynamic Optima." Resources and Energy. Vo1. 1.

Ciriacy-Wantrup, S. V. 1968. Resource Conservation: Economics and Policies. Berkeley, CA: University of California.

Georgescu-Roegen, Nicholas. 1971. The Entropy Law and the Economics Process. Cambridge, MA: Harvard University Press.

Gilliland, Martha, ed. 1978. Energy Analysis: A New Public Policy Tool. Boulder, CO: Westview Press.

Hertzmark, D. I. 1978. "Economics, Thermodynamics, and the Allocation of Energy." Unpublished doctoral dissertation, University of Wisconsin.

Hicks, J. R. 1976. "Some Questions of Time in Economics." Tang, A. M.; Westfield, F. M.; Worley, J. S. Evolution, Welfare, and Time in Economics. Lexington, MA: Heath.

Huettner, D. 1976. "Net Energy Analysis: An Economic Assessment." Science. Vol. 192 (no. 4235).

International Federation of Institutes of Advanced Study (IFIAS). 1978. ."Energy Ana1ysis and Economics." Resources and Energy. Vol. 1.

Intriligator, M. D. 1971. Mathematical Optimization and Economic Theory. Englewood Cliffs, NJ: Prentice-Ha11.

Page, Talbot. 1977. Conservation and Economic Efficiency. Baltimore, MD: Johns Hopkins Unfversity.

Enz, C. P., ed. 1973. Pauli Lectures on Physics. Vol. III. Boston, MA: MIT Press.

Robinson, J. V. 1962. Essays in the Theory of Economic Growth. New York: St. Martins. 
Spreng, Daniel T. 1978. On Time, Information, and Energy Conservation. Oak Ridge, TN: Institute for Energy Analysis, Oak Ridge Associated Universities.

Thomas, J. A. G., ed. 1977. Energy Analysis. Boulder, Co: Westview Press. 


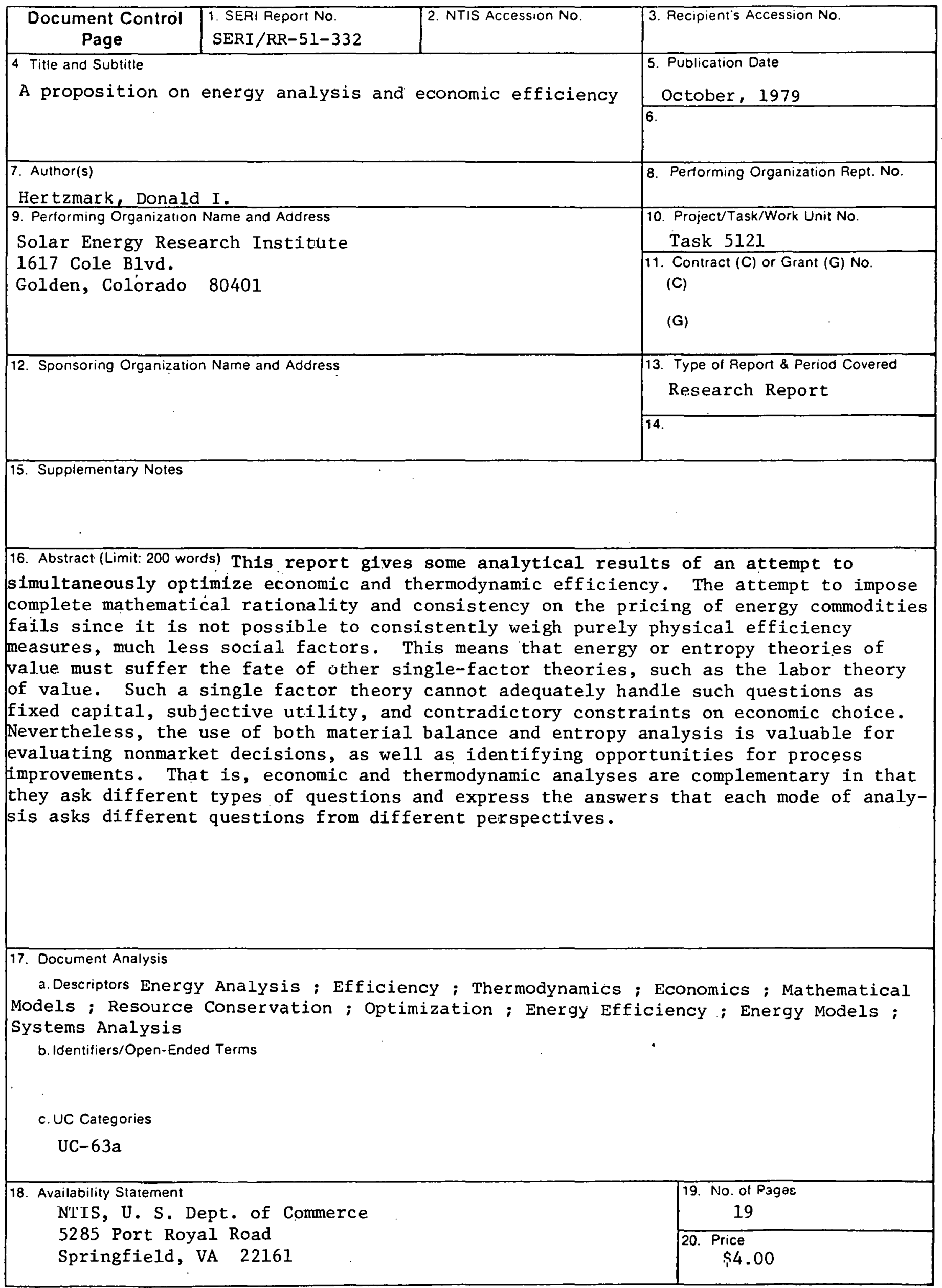

